\title{
Local Resources and Procurement Practices in Humanitarian Supply Chains: An Empirical Examination of Large Scale House Reconstruction Projects*
}

\author{
Aristides Matopoulos ${ }^{\dagger}$ \\ Engineering Systems \& Management Group, School of Engineering \& Applied Science, \\ Aston University, Aston Triangle, Birmingham B4 7ET, UK. \\ e-mail: a.matopoulos@aston.ac.uk \\ Gyöngyi Kovács \\ Humanitarian Logistics and Supply Chain Research Institute (HUMLOG Institute), \\ Hanken School of Economics, Helsinki, Finland \\ e-mail: kovacs@hanken.fi
}

Odran Hayes

WMH, 3 Rivermill, Sheetland Road, Termonfeckin, County Louth, Ireland e-mail: ohayes@esatclear.ie

\footnotetext{
${ }^{*}$ The authors would like to thank the European Agency for Reconstruction for access to their data and their kind support.

${ }^{\dagger}$ Corresponding author.
} 


\begin{abstract}
Different procurement decisions taken by relief organizations can result in considerably different implications in regards to transport, storage, and distribution of humanitarian aid and ultimately can influence the performance of the humanitarian supply chain and the delivery of the humanitarian aid. In this paper we look into what resources are needed and how these resources evolve in the delivery of humanitarian aid. Drawing on the resource-based view of the firm we develop a framework to categorize the impact of local resources on the configuration of humanitarian supply chains. In contrast to other papers, the importance of localizing the configuration of the humanitarian supply chain is not only conceptually recognized, but empirical investigations are also provided. In terms of methodology, this paper is based on the analysis of secondary data from two housing reconstruction projects. Findings indicate that the use of local resources in humanitarian aid has positive effects on programs' overall supply chain performance and these effects are not only related to the macroeconomic perspective, but benefits expand to improvements related to the use of knowledge. At the same time it was found that local sourcing often comes with a number of problems. For example, in one of the cases significant problems existed, which were related to the scarcity of local supplies. Both housing reconstruction projects have indicated the continuous need for changes throughout the programs as a dynamic supply chain configuration is important for the long-term sustainability of reconstruction aid.
\end{abstract}

[Submitted: October 30, 2012. Revised: September 9, 2013; January 17, 2014. Accepted February 6, 2014.]

Subject Areas: Supply Chain Design, Housing Reconstruction, Disaster Relief, Humanitarian Supply Chains, Procurement Practises, Resource-Based View

\title{
INTRODUCTION
}

Natural and man-made disasters have affected 2.9 billion and killed 1.2 million people between 2000 and 2012 and have resulted in damage of 1.7 trillion USD during the same time period (UNISDR, 2013). Common to almost all humanitarian crises is the need to supply to an increased number of 
recipients with humanitarian assistance, often urgent, which can take several forms from food and clean water to shelter and health services. In this context, decisions on what is procured, from where, when, by whom, and in what way, become critical not only because of the potential logistics implications (e.g. transport arrangements, distribution to beneficiaries) (Jahre \& Spens, 2007a; Balcik \& Beamon, 2008), but also because of the vast implications and the wider impact that these decisions may have on local communities (Jahre \& Spens, 2007b; Gatignon, van Wassenhove, \& Charles, 2010).

Despite some initial research efforts in understanding procurement practices in disaster relief (Long \& Wood, 1995; Jahre \& Spens, 2007a, 2007b), the majority of research has concentrated on a discussion of the potential advantages of local vs. global sourcing. For example, local sourcing is said to contribute to economic growth in the disaster area (Long \& Wood, 1995; Jahre \& Spens, 2007a, 2007b), as it contributes to business growth (Skoglund \& Hertz, 2012), whilst it reduces the response time to disasters (Gatignon et al., 2010). Local sourcing of food items even ensures their cultural and legal appropriateness (Tomasini \& van Wassenhove, 2004), not to speak of counteracting potential detrimental health consequences of changes in diet.

What seems to be missing though is a better understanding of the necessary and sufficient conditions that indicate which local resources could be included in the humanitarian supply chain, and how to include them in the configuration of the supply chain. By supply chain configuration, very much like in commercial supply chains (c.f. Fisher, 1997; Fine, 1998), we refer to the way the supply chain is structured and organized with regards to some key elements such as the number and type of organizations involved, the source locations and products, the make production sites and methods, the logistics activities (e.g. delivery channels, inventory deployment), and the financial flow.

In this research we adopt an in-outside approach emphasizing on supply chain resources, capabilities, skills, and knowledge that are available internally within the humanitarian supply chain (HSC), but we also go beyond physical to human or organizational resources. The question leading this research is the following:

- What resources are needed and how do these resources evolve in the delivery of humanitarian aid? 
We address this question by developing a framework to categorize the use of local resources in HSCs drawing from the resource-based view (RBV) of the firm. This framework is then applied, and evaluated through two reconstruction programs (in the Former Yugoslav Republic of Macedonia, FYROM, and Kosovo), to man-made disasters resulting from conflicts that followed the disintegration of Yugoslavia. In considering man-made disasters and the reconstruction phase of disaster relief, we contribute to two streams of literature in HSCM that have both been under-researched (Kunz \& Reiner, 2012). The rest of the paper is organized as follows: a brief overview of disaster relief stages with particular emphasis on housing reconstruction is provided, followed by the theoretical foundations of our proposed framework as well as a review of the literature on the impact of local sourcing in HSC. Then the methodology and the cases of reconstruction in the FYROM and reconstruction in Kosovo are presented, followed by findings and conclusions.

\section{DISASTER RELIEF AND HOUSING RECONSTRUCTION}

\section{Stages in Disaster Relief}

Disaster relief, due to the self-organizing nature of human service systems (Gibbons \& Samaddar, 2009), is not a uniform process but one that consists of distinct phases. Numerous phase models have been proposed in literature, varying in level of detail as well as in their philosophy of whether the phases should be seen as a linear process, a learning loop, or a model with overlapping processes (Tatham \& Kovács, 2007; Kovács et al., 2010). There are some interesting distinctions between the phases from a supply chain perspective. Firstly, the move from emergency towards a transition to recovery is demarcated by a change in primary transportation modes used in delivering aid, in essence changing from air to road and even sea transportation (Tatham \& Kovács, 2007)—and if possible, even before that, a shift from push to pull supply chains (Sohn, Kovács, \& Spens, 2013). Overall, there is also a shift from an agility maxim in disaster relief to more planned, lean approaches in reconstruction (Taylor \& Pettit, 2009). These shifts have important repercussions for procurement practices. The shift from push to pull implies a change in sourcing from buy-to-stock to buy-todelivery-and a potential to shift from global to regional and local sourcing (Skoglund \& Hertz, 2012). The modal shift carries implications for the pipeline, speed of delivery, and customs clearance. 
Last but not least, the shift towards (leaner) reconstruction facilitates planning and routines in sourcing.

\section{Challenges in Housing Reconstruction}

Housing represents one of the greatest material losses left behind by humans who are in immediate need of shelter and relief (Johnson, Lizarralde, \& Davidson, 2006). There are four types of housing in disaster relief: Emergency shelter (within hours after the disaster), temporary shelter (within a few days), temporary housing (within weeks), and permanent housing reconstruction that would enable disaster victims to return to their homes or the same area probably within a few years (Quarantelli, 1995). Emergency and temporary shelter often refers to camp situations, though recently, humanitarian organizations (HOs) have developed shelter solutions that would enable beneficiaries to stay in their usual environment. This is obviously only possible if this environment is accessible and safe but has the advantage of beneficiaries still having access to their community, and potentially even local water and food supplies.

In the case of earthquakes and hurricanes, solid building codes can mitigate the actual impact of disasters on the built environment—in the absence of which reconstruction needs will be exacerbated (Bilham, 2010). Urbanization further adds to the impact of disasters (Majewski, Navangul, \& Heigh, 2010). However, irrespectively of the cause and type of housing, post-disaster housing reconstruction programs (HRPs), particularly in developing countries, are characterized by a number of challenges categorized in Davidson, Johnson, Lizarralde, Dikmen, \& Sliwinski (2007, p.101) as follows:

(i). A chaotic, sometimes post-conflict scene, with resources in scarce supply and with simultaneous projects being launched by various organizations (Davidson et al., 2007).

(ii). Projects are time sensitive and must be completed quickly enough to foster recovery and to satisfy donors who want to see results (Davidson et al., 2007). Reconstruction and restoration concludes "emergency" response in the disaster relief cycle (Maon, Lindgreen, \& Vanhamme, 2009), even though the latter gets more (media and donor, as well as research) attention (Jahre \& Heigh, 2008). 
(iii). The post-disaster period is seen as a good opportunity to engage in activities that will increase the level of development and reduce vulnerability to future disasters (Pettit \& Beresford, 2005), implying that projects must be sustainably implemented (Davidson et al., 2007).

\section{THEORETICAL UNDERPINNINGS OF THE USE OF LOCAL RESOURCES IN HSC}

The RBV of the firm emphasizes the role of resources (which must be valuable, rare, and inimitable) and capabilities in achieving a sustained competitive advantage (Barney, 1991). It supports the categorization and subsequent analysis of resources that has also been used in HSC literature. As Kovács \& Tatham (2009), we follow Barney’s (1991) categorization of resources into physical, human, and organizational capital when examining the impact of local resources in HSC configuration. We also consider knowledge as one more resource to achieve superior performance based on Grant (1996). In the literature the role knowledge plays in facilitating management of the supply chain has been well justified (Hult, Ketchen \& Slater, 2004; Hult, Ketchen, Cavusgi \& Calantone. 2006). As early as 1995, Long and Wood (1995) had already emphasized access to local knowledge as an important aspect of HSCs. Local partners have a better understanding and knowledge of the local culture and value system and have deeper connections with local authorities and communities (McLachlin \& Larson, 2011). The employment of local staff enables HOs to tap into local culture, constraints, and knowledge. Local knowledge of logistics service providers and their business culture, as well as the current transport infrastructure is important for last mile distribution. Knowing beneficiaries enables access to them, if for no other reason than to know their location, language, and culture.

But while RBV asserts the link between resource configurations, capabilities, and firm performance (in terms of sustained and sustainable competitive advantage; Barney, 1991; Olavarrieta \& Ellinger, 1997; Barney, Ketchen, \& Wright, 2011), here the focus is on a wider impact of HSC configuration on aid effectiveness and the continuity towards development. The very concept of sustainable competitive advantage is disputed in this context, as it is not the HSC but its impact that should be sustainable in the long run (Haavisto \& Kovács, 2013). Conceptualized as aid effectiveness, impact can be measured on a macro-economic level in terms of the stimulation of economic growth, or 
the effects of aid on living standards (Doucouliagos \& Paldam, 2005). Yet as there are often several converging HSCs operating in an area, it is difficult to attribute such impact to any of them in particular. Therefore HSCs have come to measure their impact from various perspectives, for example in light of donor expectations vs. in internal operational terms for specific programs (Haavisto \& Kovács, 2013). The common overall aim of HSCs is to serve the needs of beneficiaries, which are then broken down to specific goals for each aid program.

HSCs draw on many resources, from workforce (via volunteer databases) to materials (which may be donated, but are often managed by suppliers as vendor managed inventory) (Kovács \& Tatham, 2009). In the field, HOs typically operate through local implementing partners (IPs) or their own "local chapters" (e.g. the International Federation of Red Cross and Red Crescent Societies, IFRC, through the national Red Cross/Red Crescent/Red Crystal; or faith-based organizations through local churches or missions). These “dormant, agile cells" of international HOs (Larson, 2011), act as first responders while international aid is still just being mobilized (Majewski et al., 2010). Thus, local chapters facilitate the flow of humanitarian aid, while international HOs need to be called for by the government before entering a country (Kovács \& Tatham, 2009). At the same time, procurement itself is seen as a VRIN (valuable, rare, inimitable and nonsubstitutable) resource, or as Ramsay (2001) describes it, purchasing skills are hard to replicate if not inimitable, and purchasing is therefore an important capability; therefore HOs tend to maintain central control of procurement decisions in spite of otherwise local chapters.

\section{UNDERSTANDING THE IMPACT OF LOCAL RESOURCES IN HSC CONFIGURATION}

The configuration of an HSC needs to be agile enough to "evolve from an initial emergency response to an ongoing reconstruction operation” (Maon et al., 2009, p.153). In this context, the cost efficiency focus alongside long-term goals of reconstruction is related to the development side of humanitarian aid (Oloruntoba \& Gray, 2006). Contrary to immediate response that emphasizes agility (Oloruntoba \& Gray, 2006), reconstruction can be planned (Hughes, 2009; Taylor \& Pettit 2009) and thus, can focus more on cost and time efficiencies. Temporary project networks form the basis for reconstruction supply chains similar to construction projects (Dubois \& Gadde, 2000; Vrijhoef \& 
Koskela, 2000; Fearne \& Fowler, 2006) and HSCs in general (Jahre \& Heigh, 2008). However, in HSCs, temporary project networks are configured without a potential reassembly of the same supply chain for further projects. Hence Tomasini (2012) refers to them as "event networks," as the constellation of participants is triggered by specific disasters. The temporary or event network nature of HSCs operating in a turbulent environment leads to an emphasis of resources and skills that can be combined into dynamic capabilities (Kovács, Tatham, \& Larson, 2012). Following the example of prior HSC literature (e.g. Kovács \& Tatham, 2009), we will review the different resources in HSCs following Barney’s (1991) distinction between physical, human, and organizational resources, before turning to the use of local resources in each of these categories.

\section{Physical Resources in HSCs}

The introduction of regional hubs through the United Nations Humanitarian Response Depots (UNHRD), as well as the recent reconfiguration of the IFRC supply chain further emphasizes regional structures (Jahre \& Heigh, 2008; Gatignon et al., 2010). But whilst the UNHRD system is mostly for regional pre-positioning of globally purchased items, the IFRC hub structure includes that aid items should be sourced regionally if not locally, though following a standard item catalogue. Both evaluations of the IFRC supply chain (Jahre \& Heigh, 2008; Gatignon et al., 2010) suggest that this reconfiguration reduced cost and response time for IFRC while it increased the effectiveness of disaster relief. The evaluations take up the "traditional” performance measures of HSCs: cost and time efficiencies, organizational and supply chain effectiveness (Beamon \& Balcik, 2008). Other performance measures to add are equity in aid (Balcik, Beamon, Krejci, Muramatsu, \& Ramirez, 2010), the (positive) impact on the local economy (Listou, 2008; Tomasini \& van Wassenhove 2004), and the cultural appropriateness of items (Long \& Wood, 1995; Pardasani, 2006). In reconstruction, the latter includes the knowledge of local building codes and appropriate technologies (Davidson et al., 2007). Again, overall, the impact of HSCs is assessed in terms of aid effectiveness. 


\section{Human Resources in HSCs}

From a human resources perspective, HOs maintained a volunteer database, or used generic volunteer databases, allowing for additions to their workforce when and where needed (Kovács \& Tatham, 2009). This is in line with the assertion that HSCs need to be agile (Oloruntoba \& Gray, 2006) to activate dormant resources (Kovács \& Tatham, 2009; Larson, 2011). Charles, Lauras and van Wassenhove (2010) summarize the agility dimensions that are emphasized in HSCs to consist of volume flexibility, delivery flexibility, mix flexibility, reactivity, and velocity.

\section{Organizational Resources in HSCs}

Another aspect to add here is the link between humanitarian aid and development beyond reconstruction. The use of local partners (chapters, IPs) and the employment and training of local staff assures not just the continuity of aid programs but also the development of a resilient population (Oloruntoba, 2005). There are numerous ways in which HSCs can include local resources in their configuration. Evaluating the resource configuration of HOs, Kovács and Tatham (2009) came to the conclusion that these were "asset light" overall. Instead of owning resources, they relied on relationships with material suppliers, logistics service providers, and, as their organizational structure permitted, local chapters or current or potential IPs. HSC agility is further ensured through the use of local chapters (Larson, 2011) and local resources overall, which support in particular reactivity through the early recognition and understanding of different needs, velocity through local sourcing that eliminates long transportation legs, and mix flexibility through access to local markets and workforce.

There are many different types of local resources, ranging from the use of local chapters and implementing partners, to local workforce, to local sourcing. The framework in Table 1 summarizes the various impacts of local physical, human, or organizational resources in HSC configuration.

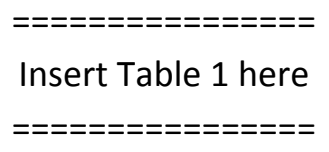


Table 1 shows general impacts of various local resources, but does not always indicate whether this impact is positive or negative. Impacts on the local economy could be positive as well as negative, hence, they need to be addressed from a systemic perspective, assessing all aspects of supply chain configuration. Tomasini and van Wassenhove (2004), for example, show how local sourcing of maize in Southern Africa increased local price levels, while it simultaneously revived otherwise moribund local industries and transportation. Altay and Ramirez (2010) see reconstruction as a way to increase local economic activities overall but Balcik et al., (2010) indicate that strong post-disaster competition for supplies inflates local prices, yet local sourcing eliminates the need for costly transportation of (globally sourced) items to the disaster area. Also, regional prepositioning reduced transportation costs to the disaster area to the extent that the cost reduction outweighed inventory carrying cost (Jahre \& Heigh, 2008). Local prepositioning and sourcing further eliminate the need for customs clearance, speeding up the response (McLachlin et al., 2009; Balcik et al., 2010). Overall, however, an increase in local market prices has a negative impact on the population, perhaps even extending the number of people who cannot afford items from the market anymore and thus become beneficiaries, dependent on aid (Balcik et al., 2010). Long and Wood (1995) further highlight that the distribution of "free" food for example disrupts local agriculture as well as local transportation systems and thus delays any development of the area towards self-sufficiency. On the other hand, incorporating a local workforce increases the direct purchasing power of beneficiaries.

Regaining self-sufficiency is a reason for local participatory models in HSC configuration (Hughes, 2009). Generally, reconstruction is seen as the phase of disaster relief in which local actors (including beneficiaries) can participate the most (Oloruntoba, 2005; Hughes, 2009). Beyond the participation of particular people or companies, Davidson et al., (2007) advocate community participation. Pardasani (2006) even shows that where community councils act as decision-makers (e.g. in reconstruction programs in the Maldives), the overall acceptance of the programs is higher. There are also other tangible aspects of community participation in reconstruction, for example, the knowledge of local building codes, and even the adaptation of building design to local site requirements (Davidson et al., 2007). Hughes (2009) further emphasizes local involvement in order to overcome contextual barriers of aid programs such as language, customs, and local and political 
issues. In this, local involvement supports the possibilities of an aid program to meet the needs of beneficiaries, and therefore succeed in achieving its goals. In the following, we will examine the impact of local resources in HSC configuration in two reconstruction programs.

\section{RESEARCH DESIGN}

Secondary data has been chosen in this study as its use can allow for the analyses of events in what would otherwise be inaccessible settings, due to practical weaknesses in accessing the research object. For example, in this research the two reconstruction projects analyzed spanned over different periods of time in different countries. In fact, a number of post-disaster studies in HSCs are based on program evaluations and secondary data analysis for the same reasons (e.g. Pardasani, 2006; Banomyong, Beresford, \& Pettit, 2009, Altay \& Ramirez, 2010, Tomasini, 2012).

This paper is based on the analysis of secondary data as reported in the European Agency of Reconstruction (further denoted as EAR), which evaluated studies of two HRPs in Kosovo and the FYROM. Both studies were conducted for the purposes of an internal analysis of the EAR (EAR, 2002, 2003) and thus did not have the aims of this research in mind. Nonetheless, they are unique studies in that they investigate the effect of the aid program by taking a more "local” view of the HSC. In other words, in contrast to other papers (e.g. Long \& Wood, 1995; Oloruntoba \& Gray, 2006) the importance of localizing the configuration of the HSC is not only conceptually recognized, but empirical investigations are also provided and documented in the EAR $(2002,2003)$ reports.

In addition, one of the authors was part of the original evaluation studies, which increases our ability to interpret the collected data (Pedraza-Martinez \& Van Wassenhove, 2012). While this gives us the reliability advantage of primary data in terms of knowing how it was collected (as argued in Calantone \& Vickery, 2010), it does not overcome the issue of the data being collected for other purposes (the EAR evaluation studies). However, according to some researchers (Calantone \& Vickery, 2010; Rabinovich \& Cheon, 2011; Tomasini, 2012) this should not necessarily be seen as a weakness as it actually increases the possibility of the existing data to be free of misconceptions and prejudice given that the purpose and the intent of the data differ from its use in the study. Therefore, 
secondary data analysis was employed as a research strategy in this paper. The original data collection involved desk research with access to files and relevant documents, as well as structured interviews (by the evaluators) with different stakeholders including task and program managers, NGOs, contractors, suppliers, and a housing reconstruction committee. Data (both qualitative and quantitative) were collected from the members of the reconstruction supply chain as listed above, including a random sample of village reconstruction committees in in-depth interviews. The research tools developed covered a wide range of issues, such as weaknesses and strengths during the selection process (targeting, participation, time-consumption, guidelines, etc.), comparison of the three reconstruction approaches (self-help, assisted self-help, contractors), and also coordination issues. Complementary data came from other NGOs in the area (12 in Kosovo and three in FYROM). Considering a potential bias in village reconstruction committees that made approval decisions as well as represented beneficiaries, these data were complemented (and triangulated) with focus group interviews in some areas. All the above data were compiled in two reports of approximately 120 pages and 40000 words long, which were analyzed with the use of NVivo software. Furthermore, the two HRPs (in Kosovo and the FYROM) were analyzed comparatively before arriving to common findings from the studies.

In order to address quality issues, which are critical in secondary data analysis, we followed the suggestions of Kovacs and Spens (2006) which call specifically for objectivity, transparency, validity, and reliability. Objectivity in data analysis was addressed by following a two stage coding process (Charmaz, 2006). The first stage started with an initial coding of the various themes that emerged deductively from the literature. In total, 25 unique themes were identified from this process, which are presented in Table 2.

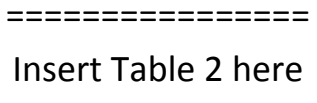

These themes may affect more than one resource types (physical, human, or organizational), which originally resulted in identifying more than 25 impacts in the literature (e.g. in Table 1 cost efficiency is relevant in all three resource types). Reliability and validity were addressed by having 
two of the three members (the author involved in data collection was excluded from this process) from the team of authors independently reading and coding the material based on the framework (Table 1) derived from the literature. In the second stage NVivo software was employed and we ran text queries based on a specific vocabulary (Table 2). The results were then filtered by the authors so as to include only the relevant references. This resulted in the identification of specific examples and supporting evidence which were then ranked based also on authors' judgement. In this stage the contribution of the author that was part of the original evaluation studies was very significant as it increased our ability to interpret the data taking into account not only the absolute number of the relevant references, but also the wording used. For example, for the theme "balancing the local economy" in the Kosovo case it was reported that the "local economy has been boosted, materials have flooded the country and local suppliers have expanded," whilst in the FYROM case a general "positive impulse to the local economy” was reported.

\section{INSIGHTS FROM THE HRPS}

\section{Background of the Kosovo Program}

Kosovo is located in the central Balkan Peninsula in Southern-Eastern Europe. It is a landlocked region and borders the FYROM to the south, Albania to the west, and Montenegro to the northwest. For many decades Kosovo was part of Yugoslavia, but the 1999 conflicts between Kosovo Albanians and Serbians resulted in Kosovo being turned into an autonomous region of Serbia, and in declaring independence in 2008. The end of the Kosovo conflict revealed a complex emergency situation characterized by refugees and large-scale housing destruction. This large-scale destruction, as well as the need to rapidly re-house families in Kosovo, demanded increased efficiency in the reconstruction effort. Without the return of families from temporary accommodation to their homes, normal life could not have resumed in Kosovo.

However, large-scale refugee returns (mostly Kosovo Albanians) from late spring 2000 added to the complexity of the situation. Also, while demand is rather predictable in reconstruction, reconstruction supply chains that deal with post-military conflicts need to take the potential of renewed hostilities into account (Taylor \& Pettit, 2009). Problems related to property rights also 
appeared. Many families who had their homes damaged or destroyed were not in the most vulnerable category of beneficiaries, but lacked the resources to fully pre-finance their speedy reconstruction. In addition, given that both HRPs targeted only a percentage of the houses damaged or destroyed, the beneficiaries that would be assisted in the reconstruction program needed to be selected carefully.

\section{Background of the FYROM Program}

The FYROM is a landlocked country located in the central Balkan Peninsula in South-Eastern Europe. It declared independence in 1991 after the disintegration of the former Yugoslavia. The country is bordered by Kosovo to the northwest, Serbia to the north, Bulgaria to the east, Greece to the south and Albania to the west. FYROM’s Housing Repair and Reconstruction Programme started in June 2001, a few months after the end of the conflict between Ethnic Albanian armed groups and government forces, which took place in the Northwest (Tetovo) and North-East of Skopje (Skopska Crna Gora). The conflict caused extensive damage to buildings in former conflict areas, including buildings of particular religious and historical significance, as well as housing infrastructure, in particular in the northern regions but also other parts of the FYROM (Kumanovo, Arachinovo, Bitola). The levels of damage to individual houses varied considerably, with many being in the more lightly damaged categories.

After the end of the conflict there was an urgent need to start quickly repairing and reconstructing the houses damaged by the conflict, thereby facilitating the return of the displaced persons, to re-establish normal living conditions and to rebuild confidence between the ethnic groups. An initial assessment carried out in the Tetovo area (April 2001) indicated about 190 houses of the first phase of conflict to be repaired or reconstructed. The assessment on the Northeast of Skopje (Skopska Crna Gora) was delayed due to the need to clear the area of mines. The 190 damaged houses in the Tetovo area accommodated about 1,500 people. The estimated 250 houses damaged in Skopska Crna Gora accommodated about 2,000 people. Later assessments however revealed a quite different picture. Table 3 summarises the key figures of both reconstruction programs.

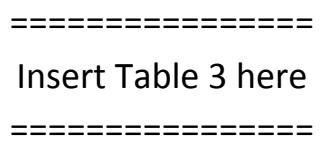


The FYROM program was initially implemented by the Commission Services with support from the existing operational centers of the EAR and relevant national and local authorities. In addition, "grant contracts" with NGO implementing partners were signed with the selected NGOs being responsible in managing assistance allocations to beneficiaries and also undertaking technical assessments and materials' voucher allocation. Moreover, NGOs were involved in the provision of technical advice and labor support, quality control and monitoring of reconstruction work, and management of any works and supply subcontracts.

\section{Analyzing the Kosovo and the FYROM Reconstruction Supply Chains}

The HRP in the FYROM differed from the Kosovo one by the fact that beneficiaries were less vulnerable and less emergency needs were seen. Also, the program had a more political role as an important precursor to the implementation of the Ohrid framework agreement and its international support. Nevertheless, from an operational point of view the two HRPs had many similarities. The following paragraphs present a comparative analysis of the two supply chains with particular reference on the procurement practices and the changes in their supply chain configurations.

\section{Procurement practices}

As Long and Wood (1995) point out, humanitarian logistics should always prioritize information from local personnel and use local expertise and labor as much as possible, so that local leaders will take personal interest in the success of operations. Local sourcing, where possible, has a positive impact on the economic situation in the region, ensuring the cultural and regional applicability of solutions as well as the potential to maintain local lifestyles (Long \& Wood, 1995). Important regional conditions for reconstruction programs include meteorological conditions of a region as well as assessments of potential natural hazards (Pande \& Pande, 2007), thus, local knowledge is essential in reconstruction (Pardasani, 2006). The IPs of both HRPs thus adopted construction labor techniques based on local communities: self-help, assisted self-help, and (local) contractors. These could be mixed; so for example a nominally self-help house could have a contractor for the roof. Assisted self-help could comprise unpaid village labor teams as well as the more typical paid mobile teams of craftspeople. 
(Kovács, Matopoulos, and Hayes (2010) provide a detailed discussion of the strengths and weaknesses of these techniques.)

While it was possible to use local labor and contractors, local sourcing of construction materials proved more difficult. In the Kosovo case, a damage assessment conducted by International Management Group in 1999 revealed problems in the supply of housing materials. On the one hand, there was an urgent need for the procurement of timber, roof tiling, and other materials for the rehabilitation of private dwellings and some public buildings. On the other hand, several problems were reported with respect to supply imports, such as embargo problems, closed borders, and delays in deliveries. The existing local market could not cope with the surge in demand for construction materials. Efforts to increase local production instead of imports were hampered by the poor supply of electricity. Consequently, only an estimated $5-10 \%$ of the construction material (mostly sand and gravel) was initially of local origin. Other materials (e.g. bricks and timber) had to be imported, mostly from neighboring countries (e.g. timber from Bulgaria).

Procurement practices of both programs did change over time. At the beginning, materials were centrally procured through an agent contracted directly by the donor, and the agents subcontracted suppliers. This resulted in a much lighter system due to the fact that IPs did not deal with large sums of money, since the procurement of material was done by the EAR directly and was taken out of the control of the IPs. In the later phases of the programs, materials supply was organized through international open tenders for each municipality. Contracted material suppliers were also in charge of all logistical activities including last mile deliveries and inventory management. IPs employed, however, a controller for warehouses, while procurement specialist teams were responsible for quality control. In conclusion, procurement was handed over to beneficiaries to empower them, though maintaining central quality control through procurement specialist teams, and further maintaining central procurement for key items such as timber. This structure resonates with the typical central procurement decision-making in HSCs with local chapters. It goes to show that procurement itself is a VRIN and even though some procurement decisions can be localized, control is maintained over key products and over quality overall. 
The supply of housing materials faced delays in deliveries mainly due to suppliers' lack of experience in trading with housing materials, but also due to the sheer scale of the HRPs. The main problem, however, remained the scarcity of supply of housing materials facing such a surge in demand. In addition, cash flow problems for local suppliers were reported as no payment in advance was allowed, leading to a situation in which suppliers had to raise $30-40 \%$ of the contract for advance upstream purchases. This problem was later tackled through the use of vouchers which could be exchanged for specified reconstruction materials at nominated supply locations (Kovács et al., 2010). The empowerment of local entities (through the use of the voucher system) had a positive impact on aid effectiveness, largely due to the shortening of delivery times as material deliveries were decoupled from the bureaucratic (and long) payment system of EAR's programs. Furthermore, given the aim of meeting the needs of beneficiaries, involving them in program design and implementation including aspects of procurement ensured the local acceptance of housing solutions. Their local expertise brings VRIN resources to the HSC in that it contextualizes the service of the HSC, leading to better program outcomes.

\section{Implication for the supply chain configuration}

With reference to the supply chain configuration of the HRPs, the FYROM program followed largely the Kosovo one. The structure of the HSC (information, financial, and material flows) for both programs is depicted in Figure 1. Both supply chains consisted of donors and governments, international agencies (the EAR and Central Housing Committee in specific), international and local NGOs (here as IPs), and community-based organizations (Municipal Housing Committees (MHCs) and Village Reconstruction Committees (VRCs) in terms of local partners and beneficiaries (beneficiary households). Other supply chain members were technical inspection and purchasing agencies, as well as material suppliers.

The configuration of the two supply chains was not static and evolved over time. For example, in the case of Kosovo, in 1999/2000 the EAR ran 20 IP partnerships (14 material suppliers), reducing to 11 in 2001 and down to four in 2002 (as the program scaled down). It is also worth noting that the housing reconstruction supply chain included other donors with separate programs, but they tended to 
operate with contractors doing the work and there was no direct link between the programs. There was coordination under the Central Housing Committee to see that there was no overlapping in the villages that they operated so as to avoid conflict between beneficiaries getting assistance using different approaches.

In terms of the financial flow, beneficiaries in both HRPs received vouchers from NGOs that they could take directly to the suppliers who would deliver to the village (or beneficiaries could collect smaller items). Interestingly, in the case of socially vulnerable beneficiaries (e.g. widows who had no male family members to assist), financial flow was directed from NGOs to beneficiaries in order to pay direct labor. Such cash and quasi-cash components of aid enable beneficiaries to make decisions based on their needs and choices. However, in some cases the NGOs would arrange with the supplier to deliver material for a number of beneficiaries at the same time and then the NGO would check on site. NGO would at the same time provide the supplier with a summary table of the materials for which they had issued vouchers. This way the supplier got a forecast of aggregated demand for coming weeks and could verify vouchers.

NGOs did not handle materials but would check that they were being delivered. The NGOs might in some cases assist with deliveries, but this was not a requirement. The technical housing inspection team (HIT) checked on quality.

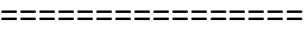 \\ Insert Figure 1 here}

With reference to the use of local labor resources, from the perspective of supply chain configuration, the interviews with suppliers, procurement agents, and IPs stressed the difficulties of a dynamic environment with a high fluctuation of staff and a continuous reconfiguration of the supply chain due to ethnic and/or political tensions. The use of local labor was an important decision in both HRPs, for several reasons. Firstly, it contributed favorably to the beneficiaries' sense of "ownership" of the reconstruction process of their houses (as expressed in high occupancy rates). Also, an important often neglected aspect of the self-reconstruction of one's own house is the psychological effect after an important loss through disaster. The act of reconstruction subscribes to the actions of 
survival and to opening windows to the future. The impact might have been augmented if a more integrated local community development model (tapping into and ensuring more synergy effects with other ongoing interventions by EAR) had been followed right from the start of the HRP.

From an organizational point of view the use of NGOs as IPs had a positive impact on both programs by giving a greater degree of flexibility on time and performance, which sometimes compensated for local institutions that were functioning less than perfectly. Increased knowledge of local standards, customs, and local authorities was also achieved by the use of locally present NGOs (this was one of the selection criteria used by the EAR to make the final contracts).

\section{Overview}

Table 4 presents an overall assessment of the various impacts (positive, negative, or neutral) of local physical, human, or organizational resources in HSC configuration for both programs. From a financial efficiency perspective both programs were successful as a result of the practices followed. In fact unit costs for reconstructed houses in Kosovo resulted in being 25\% less expensive than in Bosnia and Herzegovina’s housing reconstruction program. In comparison with other donors of the United Nations Interim Administration Mission in Kosovo (UNMIK) Housing Programme, where similar levels of rehabilitation existed, the unit cost prices used by the EAR were up to $40-45 \%$ less expensive. Despite the many common practices and results between the two programs there were also differences which are indicated in italics in Table 4.

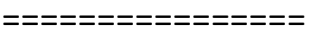

Insert Table 4 here

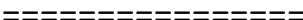

It is not surprising that the analysis of the procurement practices and of the implications for the supply chain configuration in the previous sections revealed many similarities. However, there were a few differences as well. For example, the non-use of local/regional prepositioning for physical resources in Kosovo was one of the important problems as import delays of housing materials were instigated by the closing of the FYROM border and the prior destabilization of transport infrastructure such as railways. Similarly, the use of local materials has had a somewhat positive impact in cost efficiencies in both programs, but in the case of Kosovo the impact for the local economy was 
significantly higher than the FYROM one for two main reasons. The first one was the scale of the program (see comparison in Table 3). The second reason was that the EAR took measures to ensure a maximum input from enterprises in Kosovo by advocating with the UNMIK for customs duties' relief for the import of raw materials used in the production of housing materials (e.g. windows), so as to enable emerging Kosovo manufacturers to compete with imported duty-free fabricated materials. As a result, locally originating material in the Kosovo program increased to 15-25\% in 2001 (more than double in comparison to the start). The rotation of cash in the local economy made the construction business boom, and has thus had an important impact on economic progress. Altay and Ramirez (2010) indicate this to be a general effect of reconstruction on the local economy also from the business perspective.

Positive impacts were identified by the use of local human resources. By incorporating local labor, in both programs cost improvements were realized (Kovács et al., 2010), resulting in a positive impulse to the local economy. This was particularly the case in the Kosovo program where the use of local labor was the main precursor for the privately financed housing reconstruction.

Differences were also noticed with regards to the impact of local decision making (through the engagement of VRC and MHC). In the Kosovo program a volatile and tense consultation process of IPs with and between the VRC and MHC for the selection of beneficiaries often took much longer than anticipated. This resulted in the selection process sometimes being too long, which had negative implications on the direct occupancy rate as the beneficiaries could not move to their house-to-berebuilt before the winter started.

\section{CONCLUSIONS}

This paper has explored the nature and scope of the post-war reconstruction efforts required in Kosovo and in the FYROM. The research was based on secondary data from two studies and their related reports that were developed for a different purpose than the research itself. Notwithstanding a potential bias of the EAR (2002, 2003) reports that were analyzed, there are a number of conclusions to be drawn. 
Concerning the use of local resources in humanitarian aid, it was found to have positive effects on local economies from a macro-economic perspective, contributing also to overall supply chain performance. A more "localized" reconstruction supply chain ensures increased participation in the program and the timely completion of reconstruction. What is more, from the supply chain management perspective, local participation in reconstruction through labor and materials leads to cost efficiencies. Locally available materials do not need to be imported, and transportation costs are relatively low. Local labor, on the other hand, is more cost efficient compared to salaries of expatriates contracted for reconstruction. In any case these reported positive effects should not be seen as the "absolute truth," as we recognize that there are also risks of altering or hiking local market prices, however, we did not find evidence of this in our research. Further implications can be drawn regarding the effectiveness of a reconstruction program in terms of agility and cost savings as a result of the use of multiple vs. single sources of supply for some of the materials (Chung, Talluri, \& Narasimhan, 2010).

Strictly from the procurement perspective, the results of our study emphasize procurement as a core capability of HOs. Outsourcing procurement decisions leads to beneficiary empowerment, yet quality control is to be maintained centrally. A good combination can be found in voucher systems that are tied to controlled goods and/or suppliers. Yet beneficiaries also bring VRIN resources to the table in their understanding of local customs and regulations, ensuring the acceptability of solutions.

With respect to overall challenges of supply chain configuration, both HRPs have indicated the continuous need for changes throughout a program, from facilitating the establishment of the various community organizations and supporting them with central purchasing, to handing over more and more logistical functions to beneficiaries. Not only does this confirm Hughes' (2009) view on increasing self-sufficiency of beneficiaries, but also reinforces the need for dynamic supply chain configuration in reconstruction. An interesting aspect of supply chain configuration was raised in the introduction of a voucher system in the housing reconstruction program. Not only did the voucher system empower beneficiaries to take their own decisions related to housing materials but the decoupling of financial and material flows actually reduced delivery times in the reconstruction supply chain. 
From a theoretical point of view our article has contributed by providing more depth to RBV theory explanation of the importance of knowledge as a source for improved performance. In addition to the purely economic-related benefits of local sourcing we have identified and provided examples of areas in disaster relief where knowledge-based related benefits can be realized.

The practical implication of this case is to further emphasize financial instruments (vouchers and micro-credits) as well as direct cash donations as a means to increase supply chain effectiveness. The use of the voucher system proved beneficial in one more way. It countered partly the possibility of corruption which in many cases is one of the most important problems, particularly in developing countries. In general, we believe that in supply chain research among the various flows (material, information, financial) the financial one has surprisingly not received significant interest despite its critical role. With this research we also provide empirical evidence of how innovative management of financial flows could improve performance.

Further research to test the relationships between local resources and their impact on performance as proposed in Tables 1 and 4, is also needed. For example, it would be interesting to investigate the relative importance of the local resources and whether there are specific combinations among these resources that lead to improved performance. Finally, given that humanitarian crises, particularly reconstruction projects, are not only contextually (in terms of different events) but also geographically and culturally affected we believe that more case study research (both primary and secondary) is needed.

Altay and Ramirez (2010) indicated the importance of reconstruction from the perspective of local business. An important aspect here is the restoration of local business in order to mitigate the disruption a disaster caused in any supply chain. Global supply chains are inevitably exposed to disruptions due to disasters anywhere in the world, and it is in their interest that their suppliers survive, and perhaps even more, that their markets in these areas get back on track. Most importantly, incorporating local resources in the configuration of the humanitarian supply chain contributes to the survival of a local supplier base. Further research is needed on the disaster vulnerability of global, commercial supply chains, enabling cross-learning between HSCs and SCM overall. 


\section{REFERENCES}

Altay, N., \& Ramirez, A. (2010). Impact of disasters on firms in different sectors: Implications for supply chains. Journal of Supply Chain Management, 46(4), 59-80.

Balcik, B., Beamon, B. M., Krejci, C. C., Muramatsu, K. M., \& Ramirez, M. (2010). Coordination in humanitarian relief chains: Practices, challenges and opportunities International Journal of Production Economics, 126(1), 22-34.

Banomyong, R., Beresford, A., \& Pettit, S. (2009). Logistics relief response model: The case of Thailand's tsunami affected area. International Journal of Services Technology and Management, 12(4), 414-429.

Barney, J. B. (1991). Firm resources and sustained competitive advantage. Journal of Management, 17(1), 99-120.

Barney, J. B., Ketchen, D. J. J., \& Wright, M. (2011). The future of resource-based theory: Revitalization or decline? Journal of Management, 37(5), 1299-1315.

Beamon, B., \& Balcik, B. (2008). Performance measurement in humanitarian relief chains. International Journal of Public Sector Management, 21(1), 4-25.

Bilham, R. (2010). Lessons from the Haiti earthquake. Nature 463(February), 878-879.

Calantone, R. J., \& Vickery, S. K. (2010). Introduction to the special topic forum: Using archival and secondary data sources in supply chain management research. Journal of Supply Chain Management, 46(4), 3-11.

Charles, A. Lauras, M., \& van Wassenhove, L. (2010). A model to define and assess the agility of supply chains: Building on humanitarian experience. International Journal of Physical Distribution and Logistics Management, 40(8/9), 722-741.

Charmaz, K. (2006). Constructing grounded theory: A practical guide through qualitative analysis, Sage, London.

Chung, W., Talluri, S. \& Narasimhan, R. (2010). Flexibility or cost saving? Sourcing decisions with two suppliers. Decision Sciences, 41(3), 623-650. 
Davidson, C. H., Johnson, C., Lizarralde, G., Dikmen, N., \& Sliwinski, A. (2007). Truths and myths about community participation in post-disaster housing projects. Habitat International, 31(1), 100115.

Doucouliagos, H., \& Paldam, M. (2005). The aid effectiveness literature. The sad result of 40 years of research. Working Paper No.2005-15: University of Aarhus, Denmark.

Dubois, A., \& Gadde, L. E. (2000). Supply strategy and network effects: Purchasing behaviour in the construction industry. European Journal of Purchasing and Supply Management, 6(3-4), 207-215.

EAR (2002). Kosovo Housing Reconstruction Programme 2000-2001. In C. a. E. D. E. U. Programming (Ed.), Evaluation Report.

EAR (2003). FYROM Housing Reconstruction Programme 2001-2003. In C. a. E. D. E. U. Programming (Ed.), Evaluation Report.

Fearne, A., \& Fowler, N. (2006). Efficiency versus effectiveness in construction supply chains: The dangers of 'lean' thinking in isolation. Supply Chain Management: An International Journal, 11(4), 283-287.

Fine, C. H. (1998). Clockspeed: Winning industry control in the age of temporary advantage, Basic Books.

Fisher, M.L. (1997). What Is the Right Supply Chain for Your Products? Harvard Business Review, 75(2), 105-116.

Gatignon, A., van Wassenhove, L., \& Charles, A. (2010). The Yogyakarta earthquake: Humanitarian relief through IFRC’s decentralized supply chain. International Journal of Production Economics, 126(1), 102-110.

Gibbons D. E., \& Samaddar, S. (2009). Designing referral network structures and decision rules to streamline provision of urgent health and human services. Decision Sciences, 40(2), 351-371.

Grant, R. M. (1996). Toward a knowledge-based theory of the firm. Strategic Management Journal, $17,109-122$

Haavisto, I. \& Kovács, G. (2013). Chapter 27: Sustainability in humanitarian operations. In: A. Lindgreen, S. Sen, F. Maon \& J. Vanhamme (eds.): Sustainable value chain management: 
Analyzing, designing, implementing, and monitoring for social and environmental responsibility, London, Gower Publishing, 489-507.

Hughes, K. (2009). The evolution of fully flexible supply chains, In J. Gattorna (Ed.), Dynamic supply chain alignment. London, Gower, 85-95.

Hult, G.T., Ketchen, D.J. \& Slater, S.F. (2004). Information processing, knowledge development, and strategic supply chain performance. Academy of Management Journal, 47(2), 241-253.

Hult, G. T., Ketchen, D. J., Cavusgi, S. T. \& Calantone, R. J. (2006). Knowledge as a strategic resource in supply chains. Journal of Operations Management, 24(5), 458-475.

Jahre, M. \& Heigh, I. (2008). Does the current constraints in funding promote failure in humanitarian supply chains? Supply Chain Forum: An International Journal, 9(2), 44-54.

Jahre, M. \& Spens, K. (2007a). Buy global or go local - that's the question International Humanitarian Logistics Symposium. Faringdon, UK.

Jahre, M. \& Spens, K. (2007b). Sourcing in humanitarian logistics - an exploration of problems and issues, Proceedings of the third meeting of the IMP Group in Asia, Phuket, Thailand, December 913.

Johnson, C., Lizarralde, G., \& Davidson, C. H. (2006). A systems view of temporary housing projects in post-disaster reconstruction. Construction Management and Economics, 24(4), 367-378.

Kovács, G., Matopoulos, A., \& Hayes, O. (2010). A community-based approach to supply chain design. International Journal of Logistics: Research and Applications, 13(5), 411-422.

Kovács, G., Tatham, P. \& Larson, P.D. (2012). What skills are needed to be a humanitarian logistician? Journal of Business Logistics, 33(3), 245-258.

Kovács, G., \& Spens, K. M. (2011). Trends and developments in humanitarian logistics - a gap analysis. International Journal of Physical Distribution and Logistics Management, 41(1), 32-45.

Kovács, G., \& Tatham, P. (2009). Responding to disruptions in the supply network - from dormant to action. Journal of Business Logistics, 30(2), 506-528.

Kunz, N., \& Reiner, G. (2012). A meta-analysis of humanitarian logistics research. Journal of Humanitarian Logistics and Supply Chain Management, 2(2), 116-147. 
Larson, P. D. (2011). Risky business. What humanitarians can learn from business logisticians - and vice versa London, In Christopher, M., \& Tatham, P. (Eds.) Humanitarian logistics: Meeting the challenge of preparing for and responding to disasters, UK, Kogan Page, 15-31.

Listou, T. (2008). Postponement and speculation in non-commercial supply chains. Supply Chain Forum: An International Journal, 9(2), 56-64.

Long, D. C., \& Wood, D. F. (1995). The logistics of famine relief. Journal of Business Logistics, 16(1), 213-227.

Majewski, B., Navangul, K. A., \& Heigh, I. (2010). A peek into the future of humanitarian logistics: forewarned is forearmed. Supply Chain Forum: An International Journal, 11(3), 4-18.

Maon, F., Lindgreen, A., \& Vanhamme, J. (2009). Developing supply chains in disaster relief operations through cross-sector socially oriented collaborations: A theoretical model. Supply Chain Management: An International Journal, 14(2), 149-164.

McLachlin, R., Larson, P.D., \& Khan, S. (2009). Not-for-profit supply chains in interrupted environments: The case of a faith-based humanitarian relief organisation. Management Research News, 32(11), 1050-1064.

McLachlin, R., \& Larson, P.D. (2011). Building humanitarian supply chain relationships: Lessons from practitioners. Journal of Humanitarian Logistics and Supply Chain Management, 1(1), 32-49.

Olavarrieta, S., \& Ellinger, A. E. (1997). Resource-based theory and strategic logistics research. International Journal of Physical Distribution and Logistics Management, 27(9/10), 559-587.

Oloruntoba, R. (2005). A wave of destruction and the waves of relief: Issues, challenges and strategies. Disaster Prevention and Management, 14(4), 506-521.

Oloruntoba, R., \& Gray, R. (2006). Humanitarian aid: an agile supply chain? Supply Chain Management: An International Journal, 11(2), 115-120.

Pande, R. K., \& Pande, R. (2007). Resettlement and rehabilitation issues in Uttaranchal (India) with reference to natural disasters. Disaster Prevention and Management, 16(3), 361-369.

Pardasani, M. (2006). Tsunami reconstruction and redevelopment in the Maldives. A case study of community participation and social action. Disaster Prevention and Management, 15(1), 79-91. 
Pazirandeh, A. (2011). Sourcing in global health supply chains for developing countries. Literature review and a decision making framework. International Journal of Physical Distribution and Logistics Management, 41(1), 364-384.

Pedraza-Martinez, A., \& Van Wassenhove, L. (2012). Vehicle replacement in the international committee of the red cross. Production and Operations Management, 22(2), 1-12.

Pettit, S., \& Beresford, A. (2009). Critical success factors in the context of humanitarian aid supply chains. International Journal of Physical Distribution and Logistics Management, 39(6), 450-468.

Pettit, S., \& Beresford, A. (2005). Emergency relief logistics: An evaluation of military, non-military, and composite response models. International Journal of Logistics: Research and Applications, 8(4), 313-331.

Quarantelli, E. L. (1995). Patterns of shelter and housing in US disasters. Disaster Prevention and Management, 4(3), 43-53.

Rabinovich, E., \& Cheon, S. (2011). Expanding horizons and deepening understanding via the use of secondary data sources. Journal of Business Logistics, 32(4), 303-316.

Ramsay, J. (2010). The resource based perspective, rents, and purchasing's contribution to sustainable competitive advantage. Journal of Supply Chain Management, 37(3), 38-47.

Rao, J. M. (1994). Judging givers: equity and scale in aid allocation. World Development, 22(10), $1579-1584$.

Skoglund, P., \& Hertz, S. (2012). Local sourcing in peacekeeping: A case study of Swedish military sourcing. In: Kovács, G. \& Spens, K. M. (eds.): Relief supply chain management for disasters: Humanitarian, aid, and emergency logistics, IGI Global, Hershey, PA/USA, 103-122.

Sohn, M., Kovács, G., \& Spens, K. (2013). Supply chain design with an exit strategy - health care humanitarian supply chains in Ethiopia. In LRN 2013 Conference Proceedings, forthcoming.

Tatham, P., \& Kovács, G. (2007). The humanitarian supply network in rapid onset disasters. The humanitarian supply network in rapid onset disasters. In: Halldórsson, Á. \& Stefánsson, G. (eds.): Proceedings of the 19th annual conference for Nordic researchers in logistics, NOFOMA 2007, Reykjavík, Iceland, 1059-1074. 
Taylor, D., \& Pettit, S. (2009). A consideration of the relevance of lean supply chain concepts for humanitarian aid provision. International Journal of Services Technology and Management, 12(4), $430-444$.

Thomas, A., \& Kopczak, L. (2005). From logistics to supply chain management. The path forward in the humanitarian sector. White Paper: Fritz Institute.

Tomasini, R. (2012). Informal learning framework for secondments. Logistics lessons from disaster relief operations. Doctoral dissertation Nr 250, Hanken School of Economics.

Tomasini, R., \& van Wassenhove, L. (2004). Genetically modified (GM) food donations and the cost of neutrality: Logistics response to the 2002 food crisis in Southern Africa, accessed October 7, 2011, available at http://www.insead.edu/facultyresearch/centres/isic/010HRG.pdf.

Tomasini, R., \& van Wassenhove, L. (2009). From preparedness to partnerships: case study research on humanitarian logistics. International Transactions in Operational Research, 16(5), 549-559.

van Wassenhove, L. N. (2006). Blackett memorial lecture: Humanitarian aid logistics: Supply chain management in high gear. Journal of the Operational Research Society, 57(5), 475-489.

Vrijhoef, R., \& Koskela, L. (2000). The four roles of supply chain management in construction. European Journal of Purchasing and Supply Management, 6(3-4), 169-178.

UNISDR (2013). Disaster impacts, 2000-2012 - Graphic. The United Nations office for disaster risk reduction, $\quad$ accessed $\quad$ Mar 12, 2013, available at http://www.preventionweb.net/files/31737 20130312disaster20002012copy.pdf. 
Figure 1: The Kosovo and FYROM generic housing reconstruction supply chains (authors' own elaboration based on EAR (2002, 2003)).

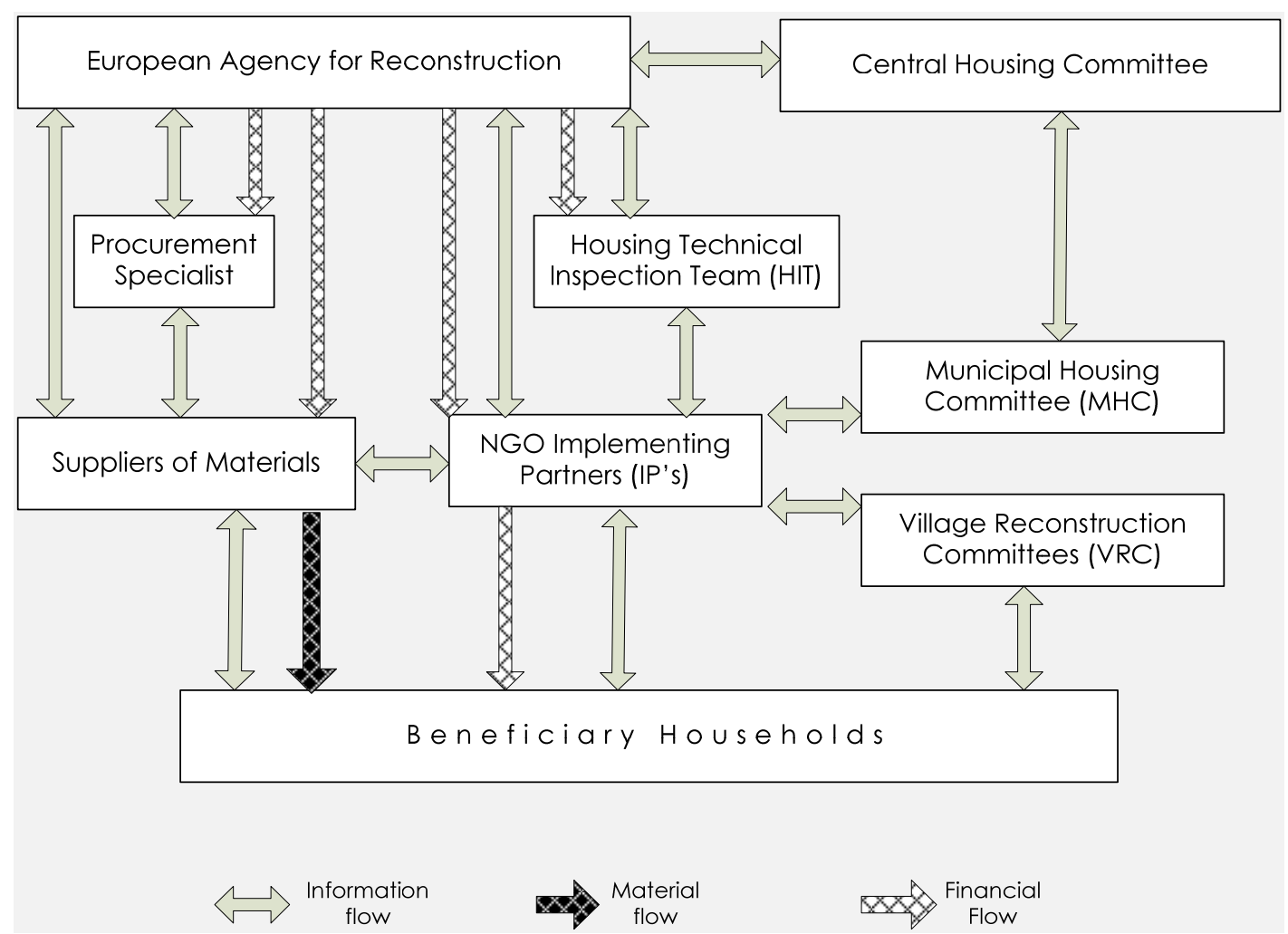


Table 1: A framework for analyzing the impact of local resources.

\begin{tabular}{|c|c|c|c|}
\hline $\begin{array}{l}\text { Type of } \\
\text { resource }\end{array}$ & $\begin{array}{l}\text { Local resources in } \\
\text { HSC configuration }\end{array}$ & Impact & References \\
\hline \multirow[t]{9}{*}{ Physical } & \multirow{4}{*}{$\begin{array}{l}\text { Local/regional } \\
\text { prepositioning }\end{array}$} & Immediate/early availability (speed of response, lead times) & Gatignon et al. (2010); Hughes (2009); Kovács and Tatham (2009); Majewski et al. (2010) \\
\hline & & Cost efficiency & Gatignon et al. (2010); McLachlin and Larson (2011); Majewski et al. (2010) \\
\hline & & Effectiveness of the response & Gatignon et al. (2010); McLachlin and Larson (2011) \\
\hline & & Adaptation to local needs & Tomasini and van Wassenhove (2009) \\
\hline & \multirow[t]{5}{*}{ Use of local materials } & Cultural appropriateness of items & Long and Wood (1995); Pardasani (2006) \\
\hline & & Including the use of local technologies & Davidson et al. (2007); Kovács et al. (2010) \\
\hline & & Gatekeeping, waste avoidance & Balcik et al. (2010) \\
\hline & & Balancing the local economy & Long and Wood (1995); Maon et al. (2009); Tomasini and van Wassenhove (2004) \\
\hline & & Cost efficiency & Bilham (2010) \\
\hline \multirow[t]{8}{*}{ Human } & \multirow[t]{8}{*}{ Local staff } & Knowledge of local culture & $\begin{array}{l}\text { Gatignon et al. (2010); Kovács et al. (2010); Kovács and Spens (2011); Kovács and Tatham (2009); } \\
\text { McLachlin and Larson (2011); Oloruntoba (2005); Pardasani (2006) }\end{array}$ \\
\hline & & Knowledge of local needs & Davidson et al. (2007); Kovács and Tatham (2009); Larson (2011); Pardasani (2006) \\
\hline & & Knowledge of local authorities & Long and Wood (1995); McLachlin and Larson (2011); Oloruntoba (2005) \\
\hline & & Access to beneficiaries & Gatignon et al. (2010); van Wassenhove (2006) \\
\hline & & Stimulation of economic growth through employment & Bilham (2010); Kovács et al. (2010) \\
\hline & & Beneficiary satisfaction & Kovács et al. (2010) \\
\hline & & $\begin{array}{l}\text { Capacity building for long-term effects (e.g. continuity and } \\
\text { resilience) }\end{array}$ & $\begin{array}{l}\text { Bilham (2010); Gatignon et al. (2010); Hughes (2009); Kovács and Spens (2011); Majewski et al. (2010); } \\
\text { Oloruntoba (2005); Pettit and Beresford (2009); Tomasini and van Wassenhove (2009), van Wassenhove (2006) }\end{array}$ \\
\hline & & Cost efficiency & Bilham (2010); Kovács et al. (2010); Long and Wood (1995) \\
\hline \multirow{19}{*}{$\begin{array}{l}\text { Organi- } \\
\text { sational }\end{array}$} & \multirow{5}{*}{$\begin{array}{l}\text { Local } \\
\text { chapter/implementing } \\
\text { partner }\end{array}$} & Access to the disaster area, lead time (speed of response) & Balcik et al. (2010); Hughes (2009); Kovács and Tatham (2009); Larson (2011) \\
\hline & & Knowledge of local standards and customs & Kovács et al. (2010); Kovács and Tatham (2009); van Wassenhove (2006) \\
\hline & & Capacity building & Larson (2011); Majewski et al. (2010); Pardasani (2006) \\
\hline & & Community building & Pardasani (2006) \\
\hline & & Knowledge of local authorities & McLachlin and Larson (2011) \\
\hline & \multirow{4}{*}{$\begin{array}{l}\text { Local decision- } \\
\text { making }\end{array}$} & Community participation & Davidson et al. (2007); Johnson et al. (2006); Kovács et al. (2010); Pardasani (2006) \\
\hline & & Equity in aid & Kovács et al. (2010); Rao (1994) \\
\hline & & Beneficiary satisfaction & Kovács et al. (2010) \\
\hline & & Ownership of the decision & Long and Wood (1995); Pardasani (2006) \\
\hline & \multirow[t]{6}{*}{$\begin{array}{l}\text { Local sourcing, local } \\
\text { suppliers }\end{array}$} & Balancing the local economy & $\begin{array}{l}\text { Jahre and Spens (2007); Kovács et al. (2010); Kovács and Spens (2011); Listou (2008); Tomasini and van } \\
\text { Wassenhove (2004) }\end{array}$ \\
\hline & & Cost efficiency & Balcik et al. (2010); McLachlin and Larson (2011) \\
\hline & & Reduced need for customs clearance reducing lead times & Balcik et al. (2010); Kovács and Tatham (2009) \\
\hline & & Ensuring cultural appropriateness & Kovács et al. (2010); Long and Wood (1995); Tomasini and van Wassenhove (2004) \\
\hline & & Ensuring legal appropriateness & Tomasini and van Wassenhove (2004) \\
\hline & & Including local technical solutions & Davidson et al. (2007) \\
\hline & \multirow{4}{*}{$\begin{array}{l}\text { Local } \\
\text { distribution/LSPs }\end{array}$} & Access to remote/insecure areas & Balcik et al. (2010); Oloruntoba and Gray (2006) \\
\hline & & Knowledge of the area & Kovács et al. (2010); Kovács and Tatham (2009); Long and Wood (1995); Pettit and Beresford (2005) \\
\hline & & Stimulating economic growth & $\begin{array}{l}\text { Kovács et al. (2010); Listou (2008); Long and Wood (1995); McLachlin and Larson (2011); Tomasini and } \\
\text { van Wassenhove (2004) }\end{array}$ \\
\hline & & Cost efficiency & McLachlin and Larson (2011); Pettit and Beresford (2009) \\
\hline
\end{tabular}


Table 2: Themes and vocabulary used in the analysis and supporting references.

\begin{tabular}{|c|c|c|}
\hline Themes & Vocabulary & $\begin{array}{c}\text { References (after filtering to include only the relevant) made on } \\
\text { the themes for Kosovo/FYROM }\end{array}$ \\
\hline 1. Availability of local resources & "local resources," "resources" & $12 / 2$ \\
\hline 2. $\quad$ Cost efficiency & "cost," "cost reduction," "cost efficiency," "budget" & $30 / 33$ \\
\hline 3. Effectiveness of the response & "effectiveness" & $3 / 1$ \\
\hline 4. $\quad$ Adaptation to local needs & $\begin{array}{l}\text { "specific needs," "adaptation to local needs," "needs of } \\
\text { the population" }\end{array}$ & $1 / 0$ \\
\hline 5. Cultural appropriateness of items & "culture," "cultural" & $0 / 0$ \\
\hline 6. Use of local technologies & $\begin{array}{l}\text { "local technologies," "local systems," "local techniques," } \\
\text { "local applications" }\end{array}$ & $0 / 0$ \\
\hline 7. $\quad$ Gatekeeping, waste avoidance & "waste avoidance," "reduce waste" & $0 / 0$ \\
\hline 8. $\quad$ Balancing the local economy & "local economy," "local production," "local suppliers" & $27 / 4$ \\
\hline 9. $\quad$ Knowledge of local culture & "local culture," "customs," "tradition" & $0 / 0$ \\
\hline 10. Knowledge of local needs & "local needs," "understanding locals" & $0 / 0$ \\
\hline 11. Knowledge of local authorities & "local authorities," "councils" & $0 / 0$ \\
\hline 12. Access to beneficiaries & $\begin{array}{l}\text { "selection of beneficiaries," "access to beneficiaries," } \\
\text { "social targeting" }\end{array}$ & $17 / 14$ \\
\hline 13. Stimulation of economic growth through employment & $\begin{array}{l}\text { "increase of employment," "employment opportunities," } \\
\text { "employment" }\end{array}$ & $7 / 3$ \\
\hline 14. Beneficiary satisfaction & "dissatisfaction," "satisfaction," "satisfied" & $8 / 4$ \\
\hline $\begin{array}{l}\text { 15. Capacity building for long-term effects (e.g., continuity } \\
\text { and resilience) }\end{array}$ & "capacity," "capacity building" & $0 / 0$ \\
\hline 16. Access to the disaster area & "access to the disaster area," "restricted access," "access" & $3 / 1$ \\
\hline 17. Knowledge of local standards and customs & $\begin{array}{l}\text { "housing standards," "local customs," "village housing } \\
\text { committees" }\end{array}$ & $15 / 8$ \\
\hline 18. Community building & $\begin{array}{l}\text { "community building," "community development," } \\
\text { "develop the community" }\end{array}$ & $0 / 0$ \\
\hline 19. Community participation & "community participation," "participation" & $3 / 2$ \\
\hline 20. Equity in aid & "gender equity," "ethnic groups" & $3 / 5$ \\
\hline 21. Ownership of the decision & $\begin{array}{l}\text { "decision making," "ownership of the decision," } \\
\text { "involvement of beneficiaries" }\end{array}$ & $10 / 4$ \\
\hline 22. Reduced need for customs clearance & "customs," "imports," "clearance," "borders" & $6 / 1$ \\
\hline 23. Access to remote/insecure areas & "remote areas," "insecure areas" & $0 / 0$ \\
\hline 24. Knowledge of the area & "local knowledge" & $0 / 0$ \\
\hline 25. Stimulating economic growth & "economic growth," "stimulating economic growth" & $0 / 0$ \\
\hline
\end{tabular}


Table 3: The reconstruction programs in numbers (authors' own elaboration based on EAR (2002, 2003).

\begin{tabular}{|l|c|c|}
\hline Key figures & Kosovo & FYROM \\
\hline Houses damaged or destroyed & 120.000 & $\sim 8.100$ \\
\hline Refugees or internally displaced persons & 350.000 & 75.000 \\
\hline Total target of international programs & n.a. & 7.776 \\
\hline Total contribution of all donors & $\sim € 1$ billion & $€ 32$ million \\
\hline EAR's targeted homes & 12.000 & 1.164 \\
\hline Cost of EAR's reconstruction programs & $€ 98$ million & $€ 7.5$ million \\
\hline
\end{tabular}


Table 4: An overall assessment of the impact of local resources on both programs.

\begin{tabular}{|c|c|c|c|c|}
\hline Type of resource & $\begin{array}{l}\text { Local resources in HSC } \\
\text { configuration }\end{array}$ & Impact & Kosovo & FYROM \\
\hline \multirow[t]{2}{*}{ Physical } & $\begin{array}{l}\text { Local/regional } \\
\text { prepositioning }\end{array}$ & $\begin{array}{ll}\text { - } & \text { Immediate/early availability (speed of response, lead times) } \\
\text { - } & \text { Cost efficiency } \\
\text { - } & \text { Effectiveness of the response } \\
\text { - } & \text { Adaptation to local needs }\end{array}$ & $\begin{array}{l}++ \\
+ \\
+ \\
0\end{array}$ & $\begin{array}{l}0 \\
+ \\
+ \\
0\end{array}$ \\
\hline & Use of local materials & $\begin{array}{ll}\text { - } & \text { Cultural appropriateness of items including the use of local technologies } \\
\text { - } & \text { Gatekeeping, waste avoidance } \\
\text { - } & \text { Balancing the local economy } \\
\text { - } & \text { Cost efficiency }\end{array}$ & $\begin{array}{c}0 \\
\text { n.a. } \\
++ \\
+\end{array}$ & $\begin{array}{l}0 \\
\text { n.a. } \\
+ \\
+\end{array}$ \\
\hline Human & Local staff & $\begin{array}{ll}- & \text { Knowledge of local culture and customs, local needs and authorities } \\
\text { - } & \text { Access to beneficiaries } \\
\text { - } & \text { Stimulation of economic growth through employment } \\
\text { - } & \text { Beneficiary satisfaction } \\
\text { - } & \text { Capacity building for long-term effects (e.g., continuity and resilience) } \\
\text { - } & \text { Cost efficiency }\end{array}$ & $\begin{array}{l}0 \\
++ \\
++ \\
++ \\
0 \\
+\end{array}$ & $\begin{array}{c}0 \\
++ \\
+ \\
++ \\
+ \\
0 \\
+\end{array}$ \\
\hline \multirow[t]{4}{*}{ Organizational } & $\begin{array}{l}\text { Local chapter/implementing } \\
\text { partner }\end{array}$ & $\begin{array}{ll}- & \text { Access to the disaster area, lead time (speed of response) } \\
\text { - } & \text { Knowledge of local standards and customs } \\
\text { - } & \text { Capacity building and community building } \\
- & \text { Knowledge of local authorities } \\
\end{array}$ & $\begin{array}{c}+ \\
+ \\
++ \\
0 \\
++\end{array}$ & $\begin{array}{c}+ \\
+ \\
++ \\
0 \\
++\end{array}$ \\
\hline & Local decision-making & $\begin{array}{ll}- & \text { Community participation } \\
- & \text { Equity in aid } \\
- & \text { Ownership of the decision } \\
\end{array}$ & $\begin{array}{l}++ \\
- \\
+ \\
\end{array}$ & $\begin{array}{l}++ \\
+ \\
+ \\
\end{array}$ \\
\hline & $\begin{array}{l}\text { Local sourcing, local } \\
\text { suppliers }\end{array}$ & $\begin{array}{ll}- & \text { Balancing the local economy } \\
\text { - } & \text { Cost efficiency } \\
\text { - } & \text { Reduced need for customs clearance reducing lead times } \\
\text { - } & \text { Ensuring cultural and legal appropriateness including local technical } \\
& \text { solutions }\end{array}$ & $\begin{array}{l}++ \\
- \\
+ \\
0\end{array}$ & $\begin{array}{l}++ \\
- \\
+ \\
0\end{array}$ \\
\hline & Local distribution/LSPs & $\begin{array}{ll}- & \text { Access to remote/insecure areas } \\
\text { - } & \text { Knowledge of the area } \\
\text { - } & \text { Stimulating economic growth } \\
\text { - } & \text { Cost efficiency }\end{array}$ & $\begin{array}{l}0 \\
0 \\
0 \\
0\end{array}$ & $\begin{array}{l}0 \\
0 \\
0 \\
0\end{array}$ \\
\hline
\end{tabular}

*Scale: (--) negative impact, (-) somewhat negative impact, (0) neutral or incomplete data to assess, (+) somewhat positive impact, (++) positive impact, (n.a.) not applicable. 